\title{
Teachers' Perceptions on Differentiated Instruction: Do Experience, Qualification and Challenges Matter?
}

\author{
Mariyam Shareefa*, Visal Moosa, Rohani Mat Zin, \\ Nor Zaiham Midawati Abdullah and Rosmawijah Jawawi \\ University Brunei Darussalam
}

\begin{abstract}
This mixed-method study examines data gathered from 101 elementary teachers to investigate their perceptions about Differentiated Instruction (DI) based on qualification and experience. The study also explores the challenges of implementing DI. A survey questionnaire with both Likert-type and open-ended questions was utilised to collect data. The results indicated that teachers had a high perception on DI, while no statistically significant difference in teachers' perceptions based on their experience and qualification was identified. Additionally, lack of resources, time, support, knowledge, and class size were identified as barriers for DI implementation.
\end{abstract}

Keywords: Challenges, Differentiated Instruction (DI), Perceptions, Teacher qualification, Teaching experience.

\section{Introduction}

Students in contemporary classrooms project a wide array of difference in personal background, readiness, and interest to learn. As school performance is challenged due to these variances, teachers simply can no longer ignore the need for differentiation (Nicolae, 2014). Hence, the demand for effective instruction that can address diversity is high, and Differentiated Instruction (DI) is such an approach that is considered as a key solution for the concern (Tomlinson, 2014). In relation to the adoption of DI, robust research is available on the role of teacher variables such as teachers' overall perception about DI (Davis, 2013; Dixon et al., 2014; Santangelo \& Tomlinson, 2012), teachers' qualification and DI implementation (Kendrick-Weikle, 2014; Suprayogi, Valcke, \& Godwin, 2017), and teachers' experience and DI practices (Kendrick-Weikle, 2014; Maeng \& Bell, 2012; Suprayogi et al., 2017; Usher, 2013). However, there is little literature that specifically investigates the influence of factors such as teachers' experience and

\footnotetext{
* Corresponding author: +6738306528, Universiti Brunei Darussalam, Jalan Tungku Link, BE1410 Brunei Darussalam
} 
qualification on their perception regarding the strategies of DI. On top of this, there have been continuous reports from teachers about how challenging and difficult DI is to implement, and hence, more research is warranted to confirm the challenges teachers experience in using the strategies.

In Maldives, where the study is conducted, the New Curriculum Framework (NCF) of Maldives anticipates pivotal changes to the methods of teaching and learning in its implementation (National Institute of Education, 2012). One such change is the way how the content is delivered to the students. Catering to individual difference is one of the five pedagogical dimensions incorporated in the NCF which is closely related to the concept of DI. Taking account of the link between the above dimension and the strategies of DI, teachers must be familiar with the core concepts of DI and its implementation.

The purpose of the present study is, therefore, to explore elementary teachers' perception of DI based on their teaching experience as well as qualification. Moreover, it also intends to explore the challenges teachers experience when attempting implementation of the strategies. In this study, teachers' perception is defined in more general terms whereby it incorporates perceptions pertaining to the importance of DI, benefits of DI to students and teachers, and challenges to implementation of DI. Likewise, teaching experience was measured by the total number of years in service while qualification was measured by the teaching certification held by the participants. Subsequently, this study seeks to find answers to the following four questions.

1. How do elementary teachers perceive DI as an instructional strategy?

2. Is there any significant difference in teachers' perception of DI based on their teaching experience?

3. Is there any significant difference in teachers' perception of DI based on their educational qualification?

4. What are the perceived obstacles to differentiate instruction?

\section{Theoretical and Conceptual Framework}

As the theoretical basis, this study is grounded on the concept of the DI model recommended by Tomlinson (2014). In addition to the DI model, four main constructs/variables that are reportedly linked to DI (teachers' qualification, experience, challenges, and perception) are used in the study. These constructs are then allied together to form the conceptual framework which is directed by both theory and empirical findings.

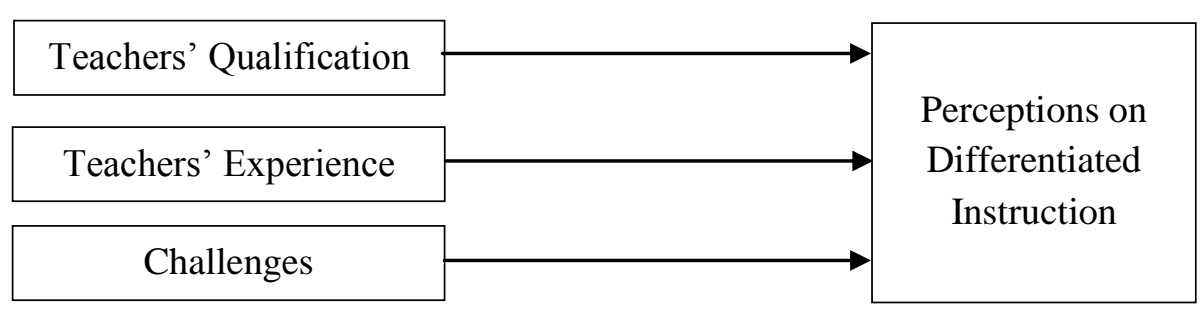

Figure1: The conceptual framework of the study 
Figure 1 presents these constructs and how they are related to each other in this study. As depicted in Figure 1, teachers' qualification and experiences are assumed to affect their perceptions on DI implementation (Burkett, 2013; Davis, 2013; Sheehan, 2011). Similarly, perceived challenges to DI implementation are also assumed to influence teachers' perception of DI. The succeeding sections provide further support for the framework using evidence from the current literature.

\subsection{Differentiated instruction}

According to Tomlinson (2014), differentiation is not a specific formula or a methodology, but rather a philosophical viewpoint. It is the deep belief and predisposition on the part of educators that regardless of the individual differences, every student can learn and reach their potential (Tomlinson, 1999).

According to the DI model, in order to maximise learning, a responsive teacher will modify and bring alterations to the instruction that allow students to get access to ideas and skills in different ways that are sensible to them (Tomlinson, 2014). As a result, students can demonstrate those ideas and skills in the learning environment. To be more specific, teachers can modify and differentiate the instruction by content (the subject matter), process (strategies adopted in delivering the lesson), product (the means by which learners demonstrate their learning), and learning environment (the physical arrangement of the classroom or learning space), based on individual differences of students (Tomlinson, 2014). One or more of these elements can be adapted at appropriate times during a lesson based on the readiness, interest, or learning profile of the students.

\subsection{The effect of teachers' qualifications and experiences on their perception of differentiated instruction}

A large body of literature is available on investigating teachers' experience and qualification that impact the implementation of DI (Casey, 2011; Dixon et al., 2014; McMillan, 2011; Suprayogi et al., 2017). However, minimal research explored the two variables - teachers' qualification and experience in relation to teachers' perception of differentiated instruction. Apparently, findings of the few available studies showed inconsistent results. Some of the studies discovered that no significant difference exists between teachers' perception based on their experience (Merawi, 2018; Suprayogi et al., 2017), while there were studies that showed that experienced teachers are familiar with a wider range of educational practices and thus, they think more positively about their instructional approaches and practices (see Liu, Jones, \& Sadera, 2010).

More specifically, in Burkett's (2013) study, a total of 11 participants who were highly qualified and who had been teaching for more than five years were asked about how they feel on using DI in their classroom. Analysis of participants' responses revealed that these qualified and experienced teachers had exceptionally positive thinking about the strategies believing that DI is essential for teaching and learning. In addition, Sheehan (2011) conducted a qualitative phenomenological study with nine K-5 elementary teachers. These highly qualified participants who have at least eight years of experience in teaching 
portrayed positive perceptions about practicing of DI in their teaching. In addition to these qualitative studies, Davis (2013) did a quantitative survey which indicated results of faculty teachers who were certified and had a minimum of a bachelors' degree, and who had the experience of 5 or more years ranking their beliefs about DI as highly positive.

In another recent study which was based on the mixed paradigm of research, Merawi (2018) investigated primary school teachers' perceptions of differentiate instruction. Aligned with the aforementioned findings, the author discovered that teachers who obtained in-service training had better perceptions than those teachers who did not obtain training on differentiated instruction. However, it was found that no significant difference was discovered based on teaching experience and teachers' perception about differentiated instruction. Explaining these inconsistent results, Moosa and Shareefa (2019) argued that, regardless of the number of years in teaching, teachers simply might not have had enough experience in using differentiated instruction appropriately in their teaching although they have been teaching for many years, thus not indicating much influence on their perception. Therefore, owing to these incongruities, more robust investigations are required to confirm and consolidate the above findings.

\subsection{Challenges for DI implementation.}

Research reveals a number of factors that lead to differentiation not being applied effectively in classrooms (Logan, 2011). For example, studies showed that large class size, fair grading of assessment for all the students, and a lack of sufficient planning time were specified as significant challenges that hinder the implementation of DI (Lange, 2009; Wan, 2017). In addition, Siam and Al-Natour (2016) discovered weak administrative, and parental support and shortages in learning resources as the additional obstacles for successful differentiation. It was revealed that the daily workload of teachers such as administrative burdens, paperwork, and documentation hinder the implementation of the DI to a great extent. Teachers also lack proper understanding or sufficient knowledge about DI strategies, and thus it stands in the way of implementation (Siam \& AlNatour, 2016). It was clearly noticed from literature, that the above-discussed concerns and challenges often result in considerable disappointment, fractious struggles and frustration among most teachers.

\section{Research Design and Methodology}

The concurrent triangulation design (Creswell, 2012) was adopted in this study as it involves analysis of both quantitative and qualitative data on teachers' perception of DI. Accordingly, the data were treated, analysed and reported separately. Data were merged only at the discussion stage in order to triangulate the findings from both the analysis.

\subsection{Research site and participants}

The study was set up in one of the atolls of Maldives. During the time of data collection, there were a total of 137 elementary teachers working in eight government schools of the atoll. Five of these schools have classes from grade 1 to 7 , while the rest has classes from grade 1 to 10 . The student population of 
these school vary from as low as P to as high as Q. One school was not included in the study as access to the school was difficult at the time of data collection

The survey was sent to all the primary teachers in the other seven schools out of which 101 completed surveys were returned back. Among these 101 teachers, majority of them $(59 \%)$ had at least Bachelors Degree-level teaching qualifications, and their teaching experience varied from 2 to 27 years. Furthermore, 95 out of 101 respondents answered the open-ended questions.

\subsection{Instrumentation, validity and reliability}

The instrument that was used in this study has three sections. Section A collected data on demographic variables such as gender, age, teaching level, experience in teaching, and level of teaching qualification. Section B (perceptions scale) of the questionnaire was designed to be answered on a Likert-type scale that ranged from 1 (Strongly Disagree) to 6 (Strongly Agree). The items in this section measured respondents' perceptions on the use of differentiated instruction in teaching. Teachers' responses with high values indicate that they have a positive perception of DI. Alternatively, low scores indicate negative perceptions. The final section (Section C) of the instrument has two open-ended questions; (1) to explore teachers' understanding of DI, and (2) to identify the perceived challenges of using DI.

The 12 items on the perception scale are a combination of items adopted from Baxter (2013), Brentnall (2016) and Usher (2013). According to these authors, all of their items were previously pilot-tested and validated by experts in the field. In addition to this, the reliability assessment of the scale conducted in the present study obtained Cronbach alpha of .669 (considered .7) indicating acceptable level of reliability (Pallant, 2007).

\subsection{Data collection and analysis}

Printed survey forms were sent to all the participating schools after obtaining consent from the respective principals. The principals assisted in completing the questionnaires and sending them back to the researcher. The returned questionnaires were coded according to the schools so that reference can be made if required in future. They were stored safely with the researchers until the data were entered into the computer for analysis.

Two primary approaches were engaged in data analysis. Firstly, the responses received for Section B was analysed using quantitative methods involving descriptive statistics of mean and standard deviation. Moreover, owing to the non-normal distribution of data, the responses were examined for differences based on teachers' experience and qualification using non-parametric techniques. Secondly, participants' responses to the open-ended questions were analysed qualitatively. The general inductive process with content analysis (Creswell, 2012) was used to analyse these responses. Participants' answers were coded into categories, and based on these categories, the major themes were generated. 


\section{Findings}

Quantitative analyses were employed in answering the first three research questions. Descriptive statistics of mean and standard deviation were used to partly answer the first research question which sought an overall teachers' perception of DI. The results of the analysis are presented in Table 1.

As seen from Table 1, overall, teachers hold a high perception of DI (mean = $4.55, \mathrm{SD}=0.37$ ). It is also observed that, on top of the high average perception, teachers did have a very high perception on the majority of the items, particularly on those regarding the benefits of DI, where the lowest among these was for item 7 (mean $=5.22, \mathrm{SD}=0.99$ ). In contrary, items pertaining to perceive challenges and difficulties to implementation of DI got a mean score lower than the overall mean of the construct where the lowest of these items was for item 10 $($ mean $=1.44, \mathrm{SD}=0.67)$ while the highest was for item $12($ mean $=3.78, \mathrm{SD}=$ 1.61).

In addition to these quantitative items, an open-ended question was given on the survey questionnaire to find out teachers' overall perception about DI, and the responses for this question were analysed qualitatively. Similar to the quantitative findings, respondents' answers for the open-ended question about their perception indicate highly positive beliefs about DI. The most prevalent theme obtained from the coding was the benefits DI provides to both teachers and students. As specified by the teachers, some examples of these studentrelated benefits included; increase in student engagement and participation, fast improvement in student learning, and student motivation etc. Benefits that are related to teachers include; helps to control student behaviour, helps classroom management, adjusts the pace of teaching and the like.

Table 1: Mean scores for teachers' perception on DI

\begin{tabular}{|c|c|c|c|c|}
\hline Item \# & Statement/ total construct & $\mathrm{N}$ & Mean & SD \\
\hline 1 & $\begin{array}{l}\text { I am responsible for teaching all students at their level } \\
\text { of readiness. }\end{array}$ & 101 & 5.32 & 0.96 \\
\hline 2 & $\begin{array}{l}\text { I believe differentiated instruction is necessary to meet } \\
\text { the needs of my students. }\end{array}$ & 100 & 5.61 & 0.79 \\
\hline 3 & $\begin{array}{l}\text { Differentiating lessons is a good way to enhance } \\
\text { academic achievement for all students. }\end{array}$ & 100 & 5.66 & 0.81 \\
\hline 4 & $\begin{array}{l}\text { Students feel more successful when lessons are } \\
\text { differentiated. }\end{array}$ & 101 & 5.45 & 0.90 \\
\hline 5 & $\begin{array}{l}\text { Students are more engaged in learning when lessons } \\
\text { are differentiated. }\end{array}$ & 101 & 5.55 & 0.75 \\
\hline 6 & $\begin{array}{l}\text { Students better understand the concept taught when } \\
\text { lessons are differentiated. }\end{array}$ & 101 & 5.52 & 0.83 \\
\hline 7 & $\begin{array}{l}\text { Teachers should be required to implement } \\
\text { differentiated instruction on a daily basis as one of the } \\
\text { best practices of teaching. }\end{array}$ & 101 & 5.22 & 0.99 \\
\hline 8 & $\begin{array}{l}\text { Using differentiated instruction has improved my } \\
\text { ability to use a variety of instructional strategies with } \\
\text { students. }\end{array}$ & 97 & 5.24 & 0.81 \\
\hline 9 & I face numerous challenges when attempting to & 100 & 1.88 & 0.96 \\
\hline
\end{tabular}


differentiate instruction in my class.

10

Planning lesson that include differentiated instruction

There are additional resources available to assist

11 teachers with differentiating instruction in a diverse class.

My supervisors are capable of assisting me with requires additional time to develop, plan, and execute.

99

1.44

0.67

99

3.64 successfully differentiating instruction.

The other themes include; positive description and personal views. Many of the participants who offered a description about DI as a strategy explicated DI as an important strategy that is flexible and that helps to cater the individual needs of students. Additionally, the respondents who expressed their personal views also had given explanations that reflect their stands about the use of DI. For instance, one teacher noted, "it is important because not all students are alike, and they don't learn in the same way". Another participant highlighted shortcomings of the model while believing its effectiveness stating that, "it is time-consuming and needs a lot of brainstorming, but when it is done right, it is very efficient".

With regard to the second and third research question, non-parametric inferential statistics were engaged in examining the differences in teachers' perception based on their experience and qualification. In this regard, the second research question examined the differences in teachers' perception of DI based on their teaching experience. For the purpose of the analysis, teachers were divided into three equal groups based on the frequency of respondents. Group 1 had 32 participants who were found to have seven or less years of teaching experience, while Group 2 had 29 participants with a teaching experience of between 8 to 12 years. The final group (Group 3) with 13 or more years of teaching experience also had 29 participants. Kruskal-Wallis Test was used to investigate the differences between these groups of teachers and the results, in Table 2, revealed that there was no statistically significant difference in teachers' perception of DI among the three groups, $X^{2}(2, n=90)=1.04, p=.56$. The median scores for the Groups 1 and 2 were 4.58 while the median for Group 3 was 4.67 indicating very close central tendencies among the groups.

Table 2: Teachers' perception of DI based on their teaching experience

\begin{tabular}{lllllll}
\hline Dimension & Teaching Experience & No & Md & df & Chi-Square $\left(X^{2}\right)$ & Sig \\
\hline \multirow{3}{*}{ Perception } & 7 or less yrs & 32 & 4.58 & & & \\
& 8 to 12 yrs & 29 & 4.58 & 2 & 1.04 & .56 \\
& 13 or more yrs & 29 & 4.67 & & & \\
\hline
\end{tabular}

Mann-Whitney $U$ test was performed (since teachers were grouped into two) to answer the third research questions which requires investigation of teachers' perception of DI based on educational qualification. The results are presented in Table 3. Teachers were re-categorised to have approximately equal number of 
respondents in either groups of qualification. According to Table 3, there is no statistically significant difference in teachers' perception between more qualified (degree and above) and less qualified (diploma and below) teachers, $\mathrm{U}=915.5, \mathrm{z}$ $=-1.015, \mathrm{p}=.31$ (median $=4.50$ and 4.58 respectively).

Table 3: Teachers' perception of DI based on their qualification

\begin{tabular}{llllcc}
\hline Perception & $\mathrm{N}$ & $\mathrm{Md}$ & $\mathrm{U}$ & $z$ & Sig \\
\hline Degree and above & 55 & 4.50 & 915.5 & -1.02 & .31 \\
Diploma and below & 38 & 4.58 & & & \\
\hline
\end{tabular}

In order to answer the research question about the challenges to DI implementation, an open-ended question was given on the questionnaire, and content analysis (Merriam, 2009) was employed to find answers for this question. Teachers explicated a wide range of reasons for them not being able to implement the strategies. From the list of these responses, five major themes were derived and they were noticed as exceptionally common for the majority of the teachers. These five major themes were namely; lack of resources, lack of time, larger class size, lack of support, and lack of knowledge. In addition, the heavy workload, flexibility in the curriculum and policies, teacher-attitude, and the high student diversity were also remarked as additional challenges which hamper implementation. As reported by the teachers, duration of the class period as well as the time they get for planning and preparations were not enough at all. Likewise, the rigidity in the system such as strict rules and procedures imposed by the policies of the Ministry of Education and the school management were reasons for DI not being implemented by those teachers.

\section{Discussion}

The subsequent paragraphs discuss answers for the four research questions in the order of their appearance in the paper.

Firstly, the results of the present study suggest that in overall, teachers perceived differentiated instruction very positively. Findings from both the quantitative and qualitative analysis of the current study were in support of each other. The survey results as well as interview findings indicated that similar to many previous studies, teachers had a strong faith in using DI for their students. Although teachers' overall perception of DI was high, they had a remarkably low perception with regard to the amount of support they get from the school management. Besides, the interview results revealed that teachers viewed implementation of DI as a challenging, time consuming, and tiring endeavour. Hence, the overall positive perception found in the present study can be attributed to teachers' beliefs with regards to the benefits of DI. Existing research is generally in support of the notion that teachers do have a positive perception on DI as is found in the current study (Maddox, 2015; Robinson et al., 2014; Usher, 2013). It is argued that the positive teachers' perception of DI reported by these studies was due to the kind of questions that were used - that they were restricted to the benefits of DI. 
On the other hand, studies which engaged a different conceptualisation of perception have come up with different findings. For instance, studies that investigated teachers' perceived ability to actually differentiate lessons reported negative or low levels of perception scores (Brentnall, 2016). Similarly, teachers' view DI implementation as complex, challenging and daunting (Subban, 2006; Tomlinson \& Imbeau, 2010). Hence, the negative or low perception of teachers on such items pertaining to challenges and support for DI implementation in the present study is supported by previous research. Consequently, it is claimed that teachers' perception of DI can vary depending on the type of inquiry that is made. If their perception of DI is studied based on the advantages of DI to students, the results are likely to be positive, whereas if it is regarding the provision of the actual implementation, the result might be negative or low.

With regard to the second and third question investigating teachers' perception of DI based on teaching experience and qualification, the present study found no statistically significant difference in teachers' perception based on the two demographic factors. Unfortunately, there does not exist much literature that yields empirical results which can be compared with these findings. Most of the studies that found teachers having a positive perception of DI were PhD dissertations and they were found with samples specifically consisted of experienced and qualified teachers (Burkett, 2013; Davis, 2013; Sheehan, 2011). Despite the positive association between perception with experience and qualification reported in those studies, they specifically did not investigate the differences among these variables. As such, they cannot be cited to argue whether or not teachers' experience and qualification have an impact on their perception of DI.

Given the existence of these findings in related studies, the findings of this study are not surprisingly different. As a matter of fact, the importance of teachers' experience and qualification, and their potential influence on teacher's perception of DI cannot be denied. The findings of this study do not, in any way, discredit the role teachers' experience and qualification can play in changing their perception of DI. The essence of the debate is that these teachers simply might not have had enough experience in using DI appropriately although they have been teaching for many years. Furthermore, the training programmes which led to their qualifications might not have covered enough content that could really have an impact on their perception of DI. Ruys, Defruyt, Rots, and Aelterman (2013)'s case study is a valid example of this justification. Conversely, the high positive perception of DI held by those teachers may be because of the topics related to individual differences that they might have studied rather than specific topics related to DI. Hence, it is postulated that, if all the teachers in the sample were pre-trained in DI and have been implementing it in their teaching, the results could have been very different. After all, it is logical to assume that there might be differences in perception between those who have personally witnessed the potential benefits of DI many times (the more experienced and more qualified) than those have just started witnessing it (the less experienced and less qualified). 
The final research question of this study focused on the perceived challenges of differentiation. The major themes gleaned from the analysis of qualitative question about the challenges are; lack of resources, lack of time, larger class size, lack of support, and lack of adequate knowledge about DI. Besides, as perceived by the teachers, the daily workload, flexibility in the curriculum and policies, teacher-attitude, and high student diversity were also considered as obstacles which stand in the way of DI implementation. Apparently, many of these challenges are in accordance with previous research (e.g. Lange, 2009; Robinson et al., 2014; Roiha, 2014; Siam \& Al-Natour, 2016). Similar to the findings of this study, availability of resources, and amount of planning time, and weak administrative support are confirmed in many other studies (e.g. Abbati's 2012; Jager, 2016; Nicolae, 2014b; Rodriguez, 2012; Siam \& Al-Natour, 2016). Additionally, Jager (2016), Maddox (2015), and Suprayogi et al. (2017) postulated class size and student diversity as barriers to fully implementing differentiated instruction.

\section{Conclusions, Implications and Recommendations}

This study portrayed an overview of how DI is perceived by elementary teachers in the research context. In particular, the study revealed that (i) teachers perceive implementation of DI as promising and beneficial for diverse learners, (ii) no statistically significant differences exist in teachers' perception of DI based on their teaching experiences and professional qualifications, and (iii) lack of resources, time constraints, larger class size, lack of support, and lack of knowledge are grave barriers that hinder the implementation of DI.

Literature shows that DI is an effective teaching strategy that can address student diversity. In the present study, the positive perceptions held by teachers regarding DI is expected to enhance adoption of such teaching practices in curriculum delivery. Previous studies have shown that when perception of DI is improved, there is a corresponding increase in implementation of instructional strategies. This implies that having positive perception about DI is instrumental in increasing the use of DI strategies in classrooms. Hence, it is recommended that school leaders should try maintaining the positivity among teachers by appropriately addressing the challenges teachers encounter as those challenges could adversely affect teachers' perceptions.

With regard to the findings showing insignificant difference in perception based on qualification and experience, it could mean that the experience and the qualification possessed by teachers (or as measured in the present study) were less related to DI. For instance, experience was measured by means of the number of years in teaching which has no specific association with experience of DI. Similarly, qualification referred to teachers' general teaching qualification rather than explicit training on DI. Consequently, it is recommended that further investigations be carried out by addressing these weaknesses in measurement of the variables. Moreover, the need to review teacher training curriculums - in both pre-service and in-service programmes -to examine for relevant and adequate knowledge of DI is emphasised. 
The results of the current study show that DI implementation is challenging. As such, the findings infer a number of implications for practicing teachers, school leaders, and policy makers. If schools are to provide high-quality education, and to provide all students fair and equal opportunities, school leaders need to find means to overcome the barriers that obstruct DI implementation. School administrations need to support teachers by reducing their workload, and providing them sufficient time to plan and implement differentiated instruction. Further, school leaders require to conduct professional development programmes on widening the horizons of teachers' knowledge on the strategies of DI so that practicing teachers can incorporate those strategies effectively into their teaching.

\section{Limitations}

The present study is restrained by certain limitations. Firstly, with regard to the design, although this is a mixed-methods study, the data were not collected in such a way that findings from one type can be used to triangulate and corroborate findings from the other. Next, sampling was restricted to a specific region of the country reducing its generalisation to other regions. Finally, the potential difference in teachers' understating of DI, that may possibly affect their perception, was not specifically investigated in this study. Hence, future research with bigger sample size conducted in different contexts and with robust mixed-methods design that enable triangulations are suggested.

\section{References}

Baxter, J. D. (2013). How teacher training affects the implementation of differentiated instruction at the elementary level. (Doctoral Dissertation, Capella University, Minneapolis, Minnesota). Available from ProQuest Dissertations \& Theses. (Order No. 3551590).

Brentnall, K. (2016). Believing everyone can learn: Differentiating instruction in mixed ability classrooms. (Doctoral Dissertation, College of Saint Elizabeth, New Jersey). Available from ProQuest Dissertations \& Theses. (Order No. 10111279).

Burkett, J. A. (2013). Teacher perception on differentiated instruction and its influence on instructional practice. (Doctoral Dissertation, Oklahoma State University, Oklahoma). Available from ProQuest Dissertations \& Theses. (Order No. 3588271).

Casey, M. (2011). Perceived efficacy and preparedness of beginning teachers to differentiate instruction. (Doctoral Dissertation, Johnson \& Wales University, Providence, Rhode Island). Available from ProQuest Dissertations \& Theses. (Order No. 3450193).

Creswell, J. W. (2012). Educational research: Planning, conducting, and evaluating quantitative and qualitative research. Boston: Pearson Education, Inc.

Davis, T. C. (2013). Differentiation of instruction in regular education elementary classes: An investigation of faculty and educational leaders' perceptions of differentiated instruction in meeting the needs of diverse learners. (Doctoral Dissertation, University of Louisiana at Lafayette, Lafayette, Louisiana). Available from ProQuest Dissertations \& Theses. (Order No. 3589970).

Dixon, F. A., Yssel, N., McConnell, J. M., \& Hardin, T. (2014). Differentiated Instruction, Professional Development, and Teacher Efficacy. Journal for the Education of the Gifted, 37(2), 111-127. https:/ / doi.org/10.1177/0162353214529042

Garrett, S. (2017). A Comparative Study between Teachers' Self-Efficacy of Differentiated Instruction and Frequency Differentiated Instruction is Implemented. (Doctoral Dissertation, Northcentral University, San Diego, California). Available from ProQuest Dissertations \& Theses. (Order No. 10257026). 
Jager, T. de. (2016). Perspectives of teachers on differentiated teaching in multi-cultural South African secondary schools. Studies in Educational Evaluation. 53, 115121.https://doi.org/10.1016/j.stueduc.2016.08.004

Joseph, S., Thomas, M., Simonette, G., \& Ramsook, L. (2013). The impact of differentiated instruction in a teacher education setting: Successes and challenges. International Journal of Higher Education, 2(3), 28-40.

Kendrick-Weikle, K. (2014). Illinois High School Teachers' Understanding and Use of Differentiated Instruction. (Doctoral dissertation). Available from ProQuest Digital Dissertations Database (Publication No. AAT 3713728).

Lange, K. (2009). Lessons learned in an inclusive classroom: A case study of differentiated instruction. (Doctoral Dissertation, Umi Dissertation Publishing, Charleston SC, United States). Available from ProQuest Dissertations \& Theses. (Order No. 3385161).

Liu, L., Jones, P. E., \& Sadera, W. A. (2010). An investigation on experienced teachers' knowledge and perceptions of instructional theories and practices. Computers in the Schools, 27, 20-34.

Logan, B. (2011). Examining differentiated instruction: Teachers respond. Research in Higher Education Journal, 13, 1-15.

Maddox, C. (2015). Elementary (K-5) teachers' perceptions of differentiated instruction. (Doctoral Dissertation). Available from Walden University.

Maeng, J. L., \& Bell, R. L. (2012). Secondary science teachers ' experiences differentiating science instruction. In Annual Meeting of the Association for Science Teacher Education, $1-41$.

McMillan, A. (2011). The relationship between professional learning and middle school teachers' knowledge and use of differentiated instruction. (Doctoral Dissertation, Walden University, Minneapolis, Minnesota). Available from Walden University.

Merawi, T. M. (2018). Primary school teachers' perceptions of differentiated instruction (DI) in Awi Administrative Zone, Ethiopia. Bahir Dar j Educ., 18(2), 152-173.

Merriam, S. B. (2009). Qualitative research: A guide to design and implementation. San Francisco, CA: Jossey-Bass.

Moosa, V., \& Shareefa, M. (2019). The impact of teachers' experience and qualification on efficacy, knowledge and implementation of differentiated instruction. International Journal of Instruction, 12(2), 587-604.

National Institute of Education. (2012). The National Curriculum Framework. Male'.

Nicolae, M. (2014). Teachers' beliefs as the differentiated instruction starting point: Research basis. Procedia - Social and Behavioral Sciences, 128, 426-431. https://doi.org/10.1016/j.sbspro.2014.03.182

Robinson, L., Maldonado, N., \& Whaley, J. (2014). Perceptions about implementation of differentiated instruction. In The Annual Mid-South Educational Research (MSERA) Conference (pp. 1-22). Knoxville, Tennessee.

Robinson, Q. E. (2017). Perceptions and adoption of differentiated instruction by elementary teachers. (Doctoral Dissertation). Available from ProQuest Dissertations \& Theses. (Order No. 10255701).

Rodriguez, A. (2012). An Analysis of elementary school teachers' knowledge and use of diffrentiated instruction. (Doctoral Dissertation, Olivet Nazarene University, Bourbonnais, Illinois). Available from Ed.D. Dissertationsl. (Paper 39).

Roiha, A. S. (2014). Teachers' views on differentiation in content and language integrated learning (CLIL): Perceptions, practices and challenges. Language and Education, 28(1), 1-18. https://doi.org/10.1080/09500782.2012.748061

Ruys, I., Defruyt, S., Rots, I., \& Aelterman, A. (2013). Differentiated instruction in teacher education: A case study of congruent teaching. Teachers and Teaching: Theory and Practice, 19(1), 93-107. https:/ / doi.org/10.1080/13540602.2013.744201 
Santangelo, T., \& Tomlinson, C. A. (2012). Teacher educators' perceptions and use of differentiated instruction practices: An exploratory investigation. Action in Teacher Education, 34(4), 309-327. https://doi.org/10.1080/01626620.2012.717032

Sheehan, J. A. (2011). Responding to student needs: The impact on classroom practice of teacher perceptions of differentiated instruction. (Doctoral Dissertation, Umi Dissertation Publishing). Available from ProQuest Dissertations \& Theses. (Order No. 3489941).

Siam, K., \& Al-Natour, M. (2016). Teacher's differentiated instruction practices and implementation challenges for learning disabilities in Jordan. International Education Studies, 9(12), 167 -181. http:/ / dx.doi.org/10.5539/ies.v9n12p167

Subban, P. (2006). Differentiated instruction: A research basis. International Education Journal, 7 (7), 935-947.

Suprayogi, M. N., Valcke, M., \& Godwin, R. (2017). Teachers and their implementation of differentiated instruction in the classroom. Teaching and Teacher Education, 67, 291-301.

Tomlinson, C. A. (1999). The Differentiated Classroom: Responding to the Needs of All Learners. Review of Educational Research (Vol. 85). Alexandria, VA: Association for Supervision and Curriculum Development.

Tomlinson, C. A. (2014). The Differentiated classroom: Responding to the Needs of All Learners. Alexandria, VA: Association for Supervision and Curriculum Development.

Tomlinson, C. A., \& Imbeau, M. B. (2010). Leading and Managing A Differentiated Classroom. Virginia: ASCD Publications.

Topley, B. M. (2010). Professional development implementation: Perceptions of elementary and middle-school teachers and administrators. (Doctoral Dissertation, The University of North Dakota, Grand Forks, North Dakota). Available from ProQuest Dissertations \& Theses. (Order No. 3455225).

Usher, L. R. (2013). Teachers perception and implementation of differentiated instruction in the private elementary and middle schools. (Doctoral Dissertation, Capella University, Minneapolis, Minnesota). Available from ProQuest Dissertations \& Theses. (Order No. 3565597).

Wan, S. W. Y. (2017). Differentiated instruction: Are Hong Kong in-service teachers ready? Teachers and Teaching: Theory and Practice, 23(3), 284-311.

$\mathrm{Xu}$, S. (2012). Strategies for differentiated instruction for English learners. Using Informative Assessments Towards Effective Literacy Instruction, 1, 349-378. 